\title{
PACTO GLOBAL NO BRASIL: UMA CONFRONTAÇÃO ENTRE OS COMPROMISSOS ASSUMIDOS E OS AVANÇOS DIVULGADOS
}

\author{
S. P. B. $\operatorname{COSTA}^{1}$; M. H. M. BEZERRA ${ }^{1 *}$; C. S. M. MELO ${ }^{1}$; J. G. ARAÚJO ${ }^{1}$, D .P. B. COSTA ${ }^{2}$ \\ ${ }^{1}$ Universidade Federal do Rio Grande do Norte (UFRN) \\ ${ }^{2}$ Universidade Federal do Ceará (UECE) \\ marcelohugu@hotmail.com*
}

Artigo submetido em janeiro/2014 e aceito em abril/2016

DOI: $10.15628 /$ holos.2016.1905

\section{RESUMO}

Considerando-se a importância da construção e publicização de indicadores que possibilitem aprimorar a avaliação de práticas sustentáveis das empresas signatárias do Pacto Global, o presente estudo teve como objetivo conhecer em que medida as organizações signatárias vem prestando contas de seus avanços quanto aos compromissos assumidos no momento da adesão. A pesquisa contemplou a totalidade das pequenas e médias signatárias brasileiras, revelando-se a grave constatação de elevado grau de inadimplência no que concerne ao envio das comunicações anuais de progresso. Em seguida, por meio de um modelo de regressão logística investigou-se a possível influência de algumas variáveis na entrega destes documentos. O resultado mostrou evidências de que o setor de atuação tem efeito no cumprimento deste compromisso, porém não apresentando significância estatística. Destacou-se o elevado percentual de consultorias que não encaminharam os relatórios, enquanto as empresas do setor industrial apresentaram a maior chance de entrega dos mesmos. Em relação ao tempo de permanência, há evidências de associação estatisticamente significativa com a entrega dos relatórios.

PALAVRAS-CHAVE: sustentabilidade, pacto global, Indicadores, pequenas e médias empresas.

\section{GLOBAL COMPACT IN BRAZIL: A CONFRONTATION BETWEEN THE COMMITMENTS AND ADVANCES DISCLOSED}

\begin{abstract}
Considering the importance of building and publicizing of indicators to enhance the evaluation of sustainable practices of signatory companies of the Global Compact, the present study aimed to understand the extent to which the signatory organizations is accountable to its commitments regarding advances in time of accession. The research looked at all the small and medium Brazilian signatory, revealing the serious finding high degree of default with respect to the submission of annual progress communications. Then, using a logistic regression model
\end{abstract}

it was investigated the possible influence of some variables in the delivery of such documents. The results showed evidence that the business sector is effective in meeting this commitment, but no statistical significance. It was emphasized the high percentage of consultants who not forwarded the reports, while the industrial sector had the highest chance of delivery. Regarding the length of stay, there is evidence of a statistically significant association with the submission of reports.

KEYWORDS: sustainability; global compact; indicators; small and medium enterprises. 


\section{INTRODUÇÃO}

A busca pela sustentabilidade é um imperativo. A extração de recursos naturais e o consumismo exacerbado, aliados ao crescimento populacional exponencial, resultaram em um quadro de desequilíbrio que compromete a qualidade de vida na atualidade e a própria sobrevivência das gerações futuras.

Friedman (2010) chama a atenção para os desafios a superar em um mundo que classifica como "quente, plano e lotado", em função do aquecimento global, da ascensão de classes médias com alto padrão de consumo em todo o mundo e da população mundial de 6,7 bilhões de pessoas. Segundo a Organização das Nações Unidas - ONU, em 2050 serão mais 2,5 bilhões de habitantes (KRUGLIANSKAS et al., 2009). Bilhões de pessoas utilizando recursos naturais em larga escala, grande parte destes, não renováveis.

Diante de um quadro tão complexo, surgiram pressões cada vez mais fortes da sociedade para que fossem trilhados caminhos alternativos, que permitissem vislumbrar um futuro diferente dos cenários nefastos previstos. Estes caminhos parecem convergir para o que se denominou desenvolvimento sustentável.

Segundo relatório da Comissão Brundtland, que em 1987 constituiu o marco inicial da utilização do termo, Desenvolvimento sustentável é aquele "que satisfaz as necessidades do presente sem comprometer a capacidade das gerações futuras para satisfazer suas próprias necessidades". (BORGES et al., 2006, p.146).

Esta nova concepção de desenvolvimento implica na quebra de paradigmas até então considerados intransponíveis em uma sociedade "mercadocêntrica". O enfoque econômico estaria sendo substituído por "um conceito mais amplo de desenvolvimento sustentável, no qual as metas de crescimento estão associadas aos esforços de redução dos efeitos nocivos [...]" (STROBEL et al., 2004).

Diante de tal complexidade, torna-se preponderante o reposicionamento das estratégias empresariais, que devem buscar outras referências para atender às novas exigências legais, de mercado e da sociedade em geral. Faz-se necessária a atuação integrada envolvendo empresas, Governo e sociedade civil organizada, em face dos grandes desafios postos pelo desenvolvimento sustentável.

Nesta perspectiva, muitos esforços vêm sendo empreendidos em prol da divulgação de ações realizadas na busca pela sustentabilidade. Em virtude da importância da ONU no panorama mundial, é foco deste trabalho o Global Compact, ou pacto global, fruto da iniciativa proposta pelo então secretário da instituição, Kofi Annan, no ano 2000, durante o Fórum Econômico Mundial de Davos (BARBIERI \& CAJAZEIRA, 2008).

O acordo foi concebido como um fórum aberto à participação e agrega mais de seis mil instituições em todo o mundo, que aderem voluntariamente ao pacto. O Brasil tem a quarta maior rede de signatárias do mundo (HERZORG, 2011). Segundo registros da ONU de agosto de 2011 (www.pactoglobal.org.br), são 373 organizações signatárias no país, sendo cem pequenas e médias empresas, segmento que concentrará as análises contidas neste artigo. 
No momento em que aderem ao pacto, as organizações se comprometem a alinhar suas operações e estratégias aos dez princípios eleitos pela Organização das Nações Unidas nas áreas de direitos humanos, trabalho, meio ambiente e combate à corrupção.

A relação entre indicadores e sustentabilidade é realçada por Munasinghe e Mcneely (1995 apud ALBUQUERQUE, 2010), que valorizam a obtenção de indicadores que sejam referentes ao bem-estar, possam ser mantidos ou cresçam no tempo.

A publicização de relatórios que possam mapear a natureza e evolução das práticas empreendidas é salutar, sendo fundamental para a disseminação das experiências e também para garantir transparência às partes interessadas, entre os quais financiadores, fornecedores, clientes, comunidade em geral e o próprio governo. No entanto, a diversidade de metodologias desenvolvidas pelas organizações para avaliar suas práticas dificulta sobremaneira a comparação de seus resultados, diminuindo as condições para reconhecimento das iniciativas dignas de destaque e reduzindo as oportunidades de benchmarking que poderiam multiplicar os esforços com foco na sustentabilidade.

Visando uma maior padronização, várias iniciativas foram desenvolvidas, dentre as quais se destacam o Instituto Brasileiro de Análises Sociais e Econômicas (IBASE), o Instituto Ethos de Responsabilidade Social e o Global Reporting Initiative (GRI).

A organização do Pacto fornece padrões próprios de orientação para construção dos relatórios, denominados Comunicações de Progresso - COPs. No entanto, reconhece a validade das iniciativas supracitadas e "flexibiliza" ao aceitar inclusive prestações de contas elaboradas sob outros formatos, como por exemplo, relatórios de sustentabilidade.

Dentro das pesquisas realizadas, foram encontrados dois trabalhos que tratam sobre a avaliação dos compromissos pactuados pelas signatárias brasileiras, o primeiro com o foco na investigação das empresas paranaenses (OLIVEIRA et al., 2008) e o segundo, baseado na análise de algumas empresas de energia (FERREIRA, 2008). O fato de terem poucos estudos nessa temática motivou o nosso interesse em reportar mais detalhes sobre o assunto. Em 2012, o Encontro Brasileiro de Administração adotou como temática o Pacto Global, tendo propiciado palestras e discussões importantes, porém não foram apresentados artigos acadêmicos com este direcionamento.

O objetivo deste estudo consiste em conhecer em que medida as pequenas e médias empresas brasileiras signatárias do Pacto Global estão cumprindo as obrigações assumidas no momento da adesão ao acordo, tendo como parâmetro o envio anual dos relatórios de comunicação de progresso, e investigar a possível influência de variáveis como o número de empregados, tempo de permanência e setor da empresa na entrega destes documentos.

Espera-se contribuir para uma confrontação entre o prometido e o realizado, pois ao aderir ao pacto a empresa se compromete com a sociedade no sentido de agregar informações que corroborem para a transparência da iniciativa, devendo informar periodicamente seus progressos quanto ao alinhamento de suas operações e estratégias aos princípios estabelecidos no acordo.

O artigo está dividido da seguinte forma: Na primeira seção, apresentam-se aspectos gerais sobre o Pacto Global. A segunda seção versa sobre o uso de indicadores para avaliação de iniciativas empresariais com foco na sustentabilidade. 
Em seguida, são descritos os procedimentos metodológicos utilizados e apresentados os resultados da análise descritiva e do ajuste do modelo de regressão logística para a entrega do relatório, relacionando as variáveis supracitadas. Após a apresentação dos resultados obtidos, são tecidas análises e discussões sobre os mesmos e, finalmente apresentadas as considerações finais do estudo, limitações e recomendações para aprofundamento futuro.

\section{PROCEDIMENTOS METODOLÓGICOS}

Este estudo pode ser classificado como descritivo e quantitativo (VERGARA, 2000). Descritivo devido ao objetivo da pesquisa fazer a descrição dos dados para uma amostra de empresas signatárias do Pacto Global. Já a caracterização quantitativa deve-se à abordagem do problema utilizar recursos e métodos estatísticos para análise dos dados. Possui ainda cunho bibliográfico, pois faz uma revisão da literatura referente às pesquisas e estudos desenvolvidos na área.

A análise dos dados se subdivide em duas fases; na primeira, se apresenta um panorama descritivo caracterizando o perfil das pequenas e médias empresas signatárias do Pacto Global em 2011 e seu posicionamento em relação ao envio dos relatórios. Em seguida, através de técnicas de análise de regressão logística, busca-se identificar variáveis que influenciem a submissão dos mesmos.

Os dados foram adquiridos a partir da lista de signatárias disponibilizada no sítio eletrônico do pacto Global Brasileiro (www.pactoglobal.org.br). No sítio referenciado foi possível obter as seguintes informações sobre as empresas signatárias: se eram públicas ou privadas; a quantidade de empregados; número de COPs que haviam enviado; data em que iniciou a participação; e os documentos enviados. Casos em que não se conseguiu obter as informações a partir do site, as empresas foram consultadas diretamente.

Inicialmente foram extraídas apenas as pequenas e médias signatárias, correspondendo a um total de cem empresas, considerando-se o critério de número de empregados para classificação quanto ao porte. Em seguida, foi consultada individualmente a posição de cada empresa no que tange à documentação encaminhada para a ONU sob a forma de COPs. $O$ alto índice de inadimplência constatado levou a etapa seguinte, a construção de um modelo de regressão que pudesse identificar variáveis que possivelmente influenciem o cumprimento ou não desta obrigação.

Para a construção do modelo de regressão, será considerada variável dependente a entrega do relatório de Comunicação de Progresso - COP à ONU, sendo atribuído "0" para as empresas que não comunicaram progresso e "1" para as que o fizeram. Três variáveis independentes serão utilizadas: setor de atuação (SET), atribuindo "1" para o Comércio, "2" para Indústrias e "3" para Serviços, sendo a categoria baseline a de Serviços; o tamanho da empresa com base no número de funcionários (TAM); e o tempo de permanência no Pacto Global expresso em anos (PERM).

Foi usado o modelo de regressão logística com o objetivo de estudar a influência do número de empregados, tempo de permanência e setor da empresa na entrega do relatório. Os procedimentos do ajuste do modelo foram feitos de acordo com o sugerido por Hosmer e Lemeshow (2000 apud CORRAR et al., 2007). O software usado foi o SPSS 17.0 for Windows. 
Quadro 1: Variáveis utilizadas no modelo de regressão e suas respectivas descrições.

\begin{tabular}{|l|l|l|}
\hline Variável & Denominação & Proxy \\
\hline \multirow{3}{*}{ ECOP (dependente) } & $\begin{array}{l}\text { Entrega de relatório de } \\
\text { Comunicação de Progresso }\end{array}$ & $\begin{array}{l}\text { assumido como dummy } \\
\mathrm{D}=1 \text { : empresa enviou relatório } \\
\mathrm{D}=0 \text { : empresa não enviou relatório }\end{array}$ \\
\hline SET (Independente) & Setor de Atividade & $\begin{array}{l}1 \text { " - Comércio } \\
2 \text { " - Indústria } \\
\text { " } 3 \text { " - Serviços } \\
\text { (categoria baseline) }\end{array}$ \\
\hline TAM (Independente) & Tamanho da empresa & Número de funcionários \\
\hline PERM (Independente) & Permanência & Expresso em anos, variando entre 1 e 11 \\
\hline
\end{tabular}

Fonte: Elaborado pelos autores

O modelo foi ajustado usando o método backward; a significância dos parâmetros foi avaliada por meio da estatística de Wald e a qualidade do ajuste foi analisada por meio da estatística de Hosmer e Lemeshow.

Conforme explicitado no quadro 1, a variável dependente é a entrega do relatório do pacto global e as variáveis independentes são o número de empregados das empresas, o tempo de permanência como signatária do pacto global (em anos) e o setor da empresa. Para o setor da empresa foram consideradas as categorias: serviços, indústria e comércio, sendo a categoria baseline a de serviços. Assim, os resultados das demais categorias serão interpretados em relação à categoria serviços.

\section{REFERENCIAL TEÓRICO}

O objetivo dessa seção é apresentar as principais referências teóricas que embasam a análise da problemática descrita na seção introdutória desse artigo. Inicialmente, será realizada uma explanação sobre o Pacto Global, enfatizando suas origens e seus princípios, e, em seguida, serão abordados os pilares conceituais sobre o uso e a importância da utilização de indicadores de sustentabilidade.

\subsection{O pacto global}

O Pacto Global foi idealizado no Fórum Econômico Mundial em 1999, onde o então secretário geral das Organizações das Nações Unidas, Kofi Annan, fez um discurso convocando a iniciativa privada para realizar e difundir práticas corporativas que contribuam para o desenvolvimento sustentável. Em 2000, a iniciativa foi oficialmente criada contando com a presença de executivos seniores de 50 grandes empresas e líderes mundiais de organizações não governamentais (FERREIRA, 2008).

Para Kell (2005 apud FERREIRA, 2008), a emergência do movimento antiglobalização antes da reunião, em 1999, da Organização Mundial do Comércio (OMC) e a crise financeira asiática do final dos anos 1990, forneceram o pano de fundo para a idealização do Pacto Global.

Trata-se da maior rede voluntária de cidadania corporativa do mundo (AREVALO \& ARAVIND, 2010; HEMPHIL, 2005). Atualmente, são mais de 8.700 empresas participantes e partes interessadas, distribuídas em mais de 140 países. Conforme os dados do sitio eletrônico do Pacto Global durante a pesquisa realizada, no Brasil, 518 organizações integram a iniciativa. 
O objetivo do pacto é mobilizar a comunidade empresarial internacional para a adoção, em suas práticas de negócios, de valores fundamentais e internacionalmente aceitos para a construção de um mercado global mais inclusivo e igualitário, proporcionando o desenvolvimento sustentável através de lideranças corporativas comprometidas.

Thérien e Pouliot (2006) desdobram esse objetivo em dois: primeiro, fazer com que o setor privado adote valores nas suas práticas que abarquem áreas relevantes para o desenvolvimento sustentável e em segundo lugar, tem como objetivo facilitar a cooperação entre diversos agentes por meio de um fórum de compartilhamento de informações, promovendo os valores pregados pelas Nações Unidas.

Tendo sido concebido como um fórum aberto à participação de empresas e demais organizações, os interessados aderem voluntariamente ao compromisso de alinhar suas estratégias e operações aos dez princípios advogados pelo Pacto Global. Esses derivam da Declaração Universal de Direitos Humanos, da Declaração da Organização Internacional do Trabalho sobre Princípios e Direitos Fundamentais no Trabalho, da Declaração do Rio sobre Meio Ambiente e Desenvolvimento e da Convenção das Nações Unidas Contra a Corrupção. Tais princípios são elencados no quadro a seguir:

Quadro 2: Princípios do pacto global

\begin{tabular}{|c|c|c|}
\hline Área & & Princípio \\
\hline \multirow{2}{*}{ Direitos Humanos } & 1 & Respeitar e proteger os direitos humanos \\
\hline & 2 & Impedir violações de direitos humanos \\
\hline \multirow{4}{*}{ Princípios de Direito do Trabalho } & 3 & Apoiar a liberdade de associação no trabalho \\
\hline & 4 & Abolir o trabalho forçado \\
\hline & 5 & Abolir o trabalho infantil \\
\hline & 6 & Eliminar a discriminação no ambiente de trabalho \\
\hline \multirow{3}{*}{ Princípios de Proteção Ambiental } & 7 & Apoiar uma abordagem preventiva aos desafios ambientais \\
\hline & 8 & Promover a responsabilidade ambiental \\
\hline & 9 & Encorajar tecnologias que não agridem o meio ambiente \\
\hline Princípios contra a Corrupção & 10 & $\begin{array}{l}\text { Combater a corrupção em todas as suas formas inclusive } \\
\text { extorsão e propina }\end{array}$ \\
\hline
\end{tabular}

Fonte: Elaborado pelos autores com base em www.pactoglobal.org.br

Para engajar-se a organização deve enviar carta do seu principal executivo para o secretário geral das ONU, expressando o apoio aos princípios supracitados, bem como o compromisso de desenvolver as seguintes ações: Emitir comunicados para a imprensa para tornar o compromisso público; Incorporar os princípios na declaração da missão da empresa; Informar os funcionários, acionistas, consumidores e fornecedores; Integrar o pacto e seus princípios nos programas de desenvolvimento; e incluir o compromisso com o pacto global no relatório anual e outros documentos publicados pela empresa. A signatária deve enviar relatórios anuais comunicando os progressos obtidos, prestando contas de seus avanços por meio do documento denominado "Comunicação de Progresso", ou COP.

As COPs devem conter alguns elementos essenciais: declaração de apoio contínuo ao pacto; descrição de ações empreendidas para "implementação" dos princípios; indicadores correntes e esperados, devendo estar acessíveis, inclusive, no site da organização.

Inicialmente, a submissão do relatório era exigida no momento da adesão; com o decorrer do tempo, passou a ser concedido um ano de tolerância para o envio da primeira COP. O formato 
dos documentos também foi "flexibilizado", de forma a estimular o envio das informações. Atualmente são aceitos documentos elaborados com base no Guia de preparação disponibilizado no site do Pacto Global, podendo também ser submetidos relatórios de sustentabilidade, indicadores propostos pelo Instituto Ethos de Responsabilidade Social ou ainda compiladas conforme especificações da iniciativa internacional GLN Open Access.

Cetindamar e Husoy (2007) exaltam o papel do pacto global como canal para aprendizagem mútua entre as empresas, promovida por exemplos de boas práticas. As comunicações de progresso, portanto, devem funcionar como instrumentos para alimentação progressiva deste canal, na medida em que viabilizam o registro e posterior socialização das informações que integram os relatórios. Esses materiais possuem amplo potencial multiplicador, por estarem disponíveis para consulta não apenas por outras signatárias, mas abertas a quaisquer interessados, através do próprio sítio eletrônico.

Ao aderirem ao pacto, portanto, as organizações devem estar seguras de que enfrentarão com veemência os obstáculos que se interpuserem aos princípios do pacto e conscientes da necessidade de um realinhamento integrado de suas estratégias e operações que suportem as mudanças necessárias.

Como ferramenta para mensurar e auxiliar na manutenção dessas estratégias, se destaca os indicadores de sustentabilidade por ser uma forma de reduzir as distorções nas informações publicadas e ajudar no processo decisório das empresas signatárias do Pacto.

\subsection{Sustentabilidade e o uso de indicadores}

A pesquisa e debate sobre os indicadores de sustentabilidade começaram a se intensificar a partir da Conferência Mundial sobre o Meio Ambiente - Rio 92 - com a recomendação do capítulo 40 da Agenda 21 na implementação desse tipo de indicador para contribuir com o desenvolvimento sustentável (GUIMARÃES \& FEICHAS; 2009 SICHE et al., 2007). A importância de indicadores de sustentabilidade é a de garantir a avaliação de práticas sustentáveis por meio de medidas que considerem as dimensões ambientais, econômicas e sociais (VEIGA, 2010).

Uma das exigências do Pacto Global é que as COPs possuam avaliação de resultado, em que a mesma pode ser realizada através da definição dos indicadores de desempenho. Fato relevante devido à contribuição que esses indicadores proporcionar ao desenvolvimento sustentável, pois embora as iniciativas relacionadas a esse tema venham se multiplicado, a mensuração do grau de sustentabilidade do desenvolvimento ainda encontra dificuldades.

Corrobora com esse pensamento Braga et al., (2004), quando destacam o desafio de mensurar a sustentabilidade e chamam atenção para a necessidade de integração de informações advindas de fontes diversas.

Segundo Laszlo (2003, p. 53) "[...] os gestores têm motivos para se sentirem confundidos [...] Cada norma tem sua própria caracterização acerca da conduta nos negócios, responsabilidade ambiental, etc.".

Neste sentido, Veiga (2009) ressalta que embora tenha se passado doze anos da adoção dos Princípios de Bellagio, é impossível vislumbrar uma forma de mensurar o desenvolvimento sustentável que tenha aceitação universal, ainda que se considerasse somente 
um dos critérios estabelecidos, o "foco prático", o qual estabelece que as avaliações devam ser baseadas em um conjunto explícito de categorias que liguem perspectivas e metas a indicadores.

Afonso (2006) reconhece o crescimento do uso de indicadores de desempenho socioambiental, mas, destaca a existência de inúmeras empresas que incorporaram o conceito de sustentabilidade a seu discurso sem modificar seus processos de produção.

Sobre a construção de indicadores, Callado e Fensterseifer (2010) alertam para a necessidade de que sejam desenhados de forma a minimizar as distorções nas informações geradas e tornarem-se mais habilitados a responder importantes questionamentos dos tomadores de decisões e outros interessados.

Januzzi e Patarra (2006) relacionam 12 propriedades, cuja avaliação de aderência, não aderência ou indiferença deveria determinar o uso ou não do indicador para os propósitos almejados. Entre outros, são destacados os seguintes: validade, sensibilidade às ações previstas, confiabilidade, comunicabilidade, factibilidade operacional e comparabilidade.

Guimarães e Feichas (2009) também consideram que os indicadores de sustentabilidade tenham as seguintes características: permitir a mensuração de diferentes dimensões abrangendo a complexidade dos fenômenos sociais; participação da sociedade no processo de desenvolvimento sustentável; subsidiar o processo de tomada de decisão; e relacionar variáveis.

Valarelli (1999 apud RODRIGUES, 2010) ressalta a importância de combinar parâmetros quantitativos e qualitativos, de forma a explicitar em que medida os objetivos previstos de um projeto foram alcançados em cada nível hierárquico do marco lógico, considerando o prazo de tempo esperado e a abrangência geográfica prevista.

A importância das informações quantitativas é evidenciada também por Januzzi e Patarra (2006) quando enaltecem o papel dos indicadores intermediários, chamados indicadores-processo ou fluxo, que traduzem em medidas quantitativas o esforço operacional de alocação de recursos humanos, físicos ou financeiros (indicadores-insumo) para obtenção de melhorias efetivas de bemestar (indicadores-resultado e impacto).

Mokate (2000) contribui considerando válidos para a construção de um bom sistema de indicadores os seguintes pré-requisitos: relevância para os usuários da informação; praticidade e viabilidade; validade; confiabilidade; clareza e precisão; sensibilidade às mudanças nos objetos/comportamentos que pretende acompanhar.

Estes posicionamentos evidenciam a importância de análises que identifiquem nos relatórios encaminhados pelas signatárias indicadores bem fundamentados e que se possa assim observar vários critérios dentre os identificados na literatura pertinente, tais como factibilidade, confiabilidade, cobertura, periodicidade de atualização e transparência, desejáveis para o estímulo do benchmarking de sustentabilidade empresarial.

Acredita-se que a disseminação das práticas, respaldada por indicadores adequados, configura-se como oportunidade para a legitimação de iniciativas com foco na sustentabilidade realmente dignas de valorização. É de extrema importância, para isso, não apenas realizar avanços, mas também divulgá-los ao máximo, tornando-os acessíveis para reflexões e ajustes que propiciem o avanço das organizações pactuadas. Dessa forma, os efeitos positivos serão potencializados e multiplicados, construindo-se um círculo virtuoso. 


\section{ANÁLISE E DISCUSSÃO DOS RESULTADOS}

A partir da coleta dos dados durante a pesquisa e da execução do procedimento metodológico, os resultados da pesquisa encontram-se nas duas tabelas que são apresentadas a seguir:

Tabela 1: Caracterização das pequenas e médias signatárias, por setor.

\begin{tabular}{l|l|l|l}
\hline Setor & Empresas & Empresas que não entregaram COPs & \% Empresas que não entregaram COPs \\
\hline SERVIÇOS & 57 & 32 & 56,14 \\
\hline COMÉRCIO & 15 & 7 & 46,66 \\
\hline INDÚSTRIA & 28 & 10 & 35,71 \\
\hline
\end{tabular}

Fonte: Elaborado pelos autores

Tabela 2: Resultados do ajuste do modelo de regressão logística inicial e final para a entrega do relatório.

\begin{tabular}{|c|c|c|c|c|c|}
\hline Variável & Coeficiente & Erro-padrão & Valor-p & Exp. (Coef) & IC 95\% Exp. (Coef) \\
\hline PERM & 0,542 & 0,169 & 0,001 & 1,719 & $(1,23 ; 2,39)$ \\
\hline Setor (Serviços) & & & 0,318 & & \\
\hline Comércio & 0,299 & 0,634 & 0,638 & 1,348 & $(0,39 ; 4,67)$ \\
\hline Indústria & 0,772 & 0,511 & 0,131 & 2,164 & $(0,79 ; 5,89)$ \\
\hline TAM & 0,000 & 0,004 & 0,930 & 1,000 & $(0,99 ; 1,01)$ \\
\hline Constante & $-1,711$ & 0,608 & 0,005 & 0,181 & \\
\hline $\begin{array}{l}\text { Modelo inicial } \\
\text { Hosmer Lemeshow: 6,96 } \\
\text { Log-likelihood = -240,30 }\end{array}$ & $-p=0,541$ & & & & \\
\hline ADES (em anos) & 0,558 & 0,168 & 0,001 & 1,747 & $(1,25 ; 2,43)$ \\
\hline Constante & $-1,629$ & 0,523 & 0,002 & 0,196 & \\
\hline $\begin{array}{l}\text { Modelo final } \\
\text { Hosmer Lemeshow: } 14,4 \\
\text { Log-likelihood }=-245,74\end{array}$ & or-p $=0,07$ & & & & \\
\hline
\end{tabular}

Fonte: Elaborado pelos autores

Inicialmente, foi possível constatar um alerta grave de que $51 \%$ das organizações pesquisadas estejam em débito em 2011 no que se refere ao encaminhamento das COPs. Este quadro ameaça a efetividade e consequente credibilidade da iniciativa, condicionada à sua transparência, acreditando-se ser de fundamental importância o acompanhamento dos avanços empreendidos através de indicadores sistemáticos e confiáveis.

Com base nos dados elencados na tabela 2, há evidências de que não existe associação significativa entre o número de empregados e a entrega do relatório.

Vários pesquisadores, no entanto, demonstraram através de pesquisas associações nesse sentido, como sugerem os trabalhos de Cowen et al., (1987) e Michelon (2007). Segundo estes, o tamanho das empresas é uma variável encontrada em muitas pesquisas, positivamente associada com as evidenciações das informações socioambientais, indicando que grandes empresas possuem alto grau de evidenciação.

Michelon (2007) ressalta que este posicionamento é corroborado pelos estudos de Patten (1992), Hackston e Milne (1996). Para os autores supracitados as grandes empresas sofrem maior 
impacto dos seus stakeholders, que são as partes interessadas na atividade da empresa, diretamente e indiretamente.

Ahmed e Courtis (1999 apud MICHELON, 2007), por meio de uma análise, afirmam que o custo político e argumentos da teoria da agência demonstram que as maiores companhias são mais prováveis de evidenciar suas informações.

O tamanho das empresas é mensurado em alguns desses trabalhos pelo número de empregados, mas também com base nos valores do ativo total, receitas de vendas ou de acordo com ranking de periódicos.

Vale salientar, no que tange à investigação empreendida no trabalho ora apresentado, que a mesma foi restrita às pequenas e médias signatárias do Pacto global e tomando como base o número de funcionários, ou seja, não se sabe se a inclusão de grandes empresas levaria a resultados semelhantes aos evidenciados nos estudos supracitados.

No que se refere ao setor de atividade, mesmo não sendo estatisticamente significante a influência da variável na entrega do relatório, estima-se que a chance de uma empresa do setor industrial entregar o relatório é 2,164 vezes a chance de entrega do relatório por uma empresa do setor de serviços. Já a chance de entrega do relatório de uma empresa do setor de comércio é 1,348 vezes a chance de entrega de uma empresa do setor de serviços.

Estes resultados estão alinhados com os critérios estabelecidos pela BOVESPA para classificações concernentes ao índice de Sustentabilidade Empresarial-ISE (BOVESPA, 2008) que divide as empresas em dois níveis de impacto: alto e moderado. São consideradas como causadoras de impacto moderado as empresas de aluguel de carros, consultorias, comércio, hotéis, livrarias, papelarias, tecnologia da informação, telefonia fixa e móvel, TV por assinatura, dentre outras, enquanto as classificadas como de Alto Impacto são prioritariamente indústrias.

Dierkes e Preston (1977) demonstram que as empresas cujas atividades econômicas modificam diretamente o ambiente, como as indústrias de óleo e gás, por exemplo, são mais monitoradas quanto ao seu desempenho ambiental do que outras empresas. Michelon (2007) corrobora com essa ideia, ao afirmar que o setor de atividade de uma companhia afeta a prática de evidenciação das informações socioambientais.

Tal monitoramento, diretamente relacionado com maior chance de entrega dos relatórios pelo setor industrial, corresponde às pressões sociais e governamentais que exigem uma resposta no sentido de adotar estratégias que minimizem impactos negativos a stakeholders. Em algumas circunstâncias, a mudança organizacional constitui uma reação direta às imposições governamentais, como nos casos de adoção de novas tecnologias de controle da poluição em decorrência de regulamentações ambientais, e não pelo fato de desejar adotar aspectos socioambientais sustentáveis.

Sobre a pressão da sociedade sobre as indústrias, Hart (1996 apud HOURNEAUX et al., 2004), defende que o processo de busca da sustentabilidade a ser adotado pelas empresas deve percorrer uma sequência de três estágios fundamentais, nos quais as empresas devem buscar eficiência, sempre voltadas para um desenvolvimento sustentável: a prevenção da poluição (que envolve a mudança do controle para a prevenção e a eliminação de poluentes antes da formação dos mesmos), a zeladoria de produtos (que envolve a administração dos impactos ambientais destes produtos durante todo o ciclo de vida que percorrem e o projeto de produtos mais fáceis 
de serem recuperados, reutilizados e reciclados) e, por fim, a utilização de tecnologias limpas, ambientalmente sustentáveis.

Os efeitos das pressões sobre as organizações foram identificados por Powell e Di Maggio no artigo clássico intitulado The Iron Cage Revisited (POWELL \& DIMAGGIO, 1983), em que apresentam os mecanismos que levam ao isomorfismo, classificando-os como coercitivos, miméticos e normativos.

No que se refere à categoria baseline, constituída pelas empresas de serviço, estas possuem as menores chances de entrega dos relatórios, cabendo aqui destacar que, das cem pequenas e médias empresas signatárias do setor, 57 pertencem ao setor serviços e 33 destas são empresas de consultoria, o que significa $33 \%$ do total de organizações pesquisadas e $57,9 \%$ das empresas de serviço. No entanto, verificou-se que mais de $54 \%$ das empresas de consultoria não cumpriram em 2011 com os compromissos pactuados, não tendo prestado contas junto à ONU quanto aos eventuais progressos obtidos.

Esse fato merece uma maior atenção e reflexão, pois as empresas de consultoria, por possuírem como atividade fim o aconselhamento de organizações clientes, podem ser consideradas particularmente influentes nos processos de mudanças organizacionais. A atuação responsável no que concerne a aspectos socioambientais das empresas seria, portanto, salutar, o poder de influenciar positivamente a institucionalização de práticas inovadoras. Acredita-se que seria válido um trabalho de conscientização e acompanhamento das organizações do pacto focado no segmento de consultoria, em função de seu expressivo potencial multiplicador.

O baixo comprometimento destas, por outro lado, evidenciado pelo descumprimento das obrigações pactuadas, pode revelar uma postura oportunista de muitas organizações do tipo, que parecem buscar apelo midiático em detrimento de ações realmente sustentáveis.

Os setores de "comércio" e "indústria", como mostrado na Tabela 1, apesar de apresentarem uma porcentagem menor de empresas inadimplentes em comparação com o setor de "serviços, possuem um nível alto de empresas que deixaram de entregar suas COPs no prazo estipulado (46,66 \% e 35,71\%, respectivamente), caracterizando a fragilidade de efetivação do Pacto Global para as pequenas e médias signatárias como um todo.

Já em relação ao tempo de permanência, há evidências de associação estatisticamente significativa com a entrega do relatório sendo que para cada ano acrescentado na permanência da empresa no pacto há um acréscimo de 1,747 vezes na chance de entrega do relatório. Além disso, o resultado do teste de Hosmer Lemeshow não indica falta de ajuste do modelo (valor- $p=0,07$ ) considerando o nível de significância de $5 \%$.

Esta relação de influência está de acordo com o esperado, visto que a ONU tem como política a exclusão de signatárias que permanecem sem enviar relatórios por 2 anos. No início de 2011, foram retiradas 2.048 associadas, sendo 72 brasileiras, da sua lista de participantes, pelo motivo de não divulgação dos informes anuais sobre o que tais empresas têm feito para integrar os dez princípios do pacto à sua estratégia e às suas operações.

Um dos resultados em relação a esse quesito foi a constatação de grande número de empresas que aderiram recentemente ao pacto e encontram-se inadimplentes. Se forem consideradas apenas as 32 pequenas e médias empresas brasileiras que se integraram ao 
movimento em 2010, vinte e uma já estão em atraso em relação ao envio de COPs, o que representa mais de $65 \%$ das ingressantes nesse ano.

Outro ponto que pode estar relacionado ao acréscimo na chance de entrega do relatório por causa do tempo de permanência da empresa é a gestão do conhecimento organizacional sobre - Pacto e a percepção dos possíveis benefícios que a empresa está obtendo ao participar da iniciativa. Quanto mais tempo a empresa adota os princípios do Pacto na sua gestão, maior a chance dela obter pontos positivos junto aos seus stakeholders e com isso aumentar a intenção de permanência dentro do Pacto.

\section{CONSIDERAÇÕES FINAIS}

A crença na importância da valorização de iniciativas empresariais com foco na sustentabilidade motivou a realização deste estudo. Buscou-se conhecer a experiência do Pacto Global, apresentando-se os critérios que balizam o ingresso e manutenção das empresas como signatárias e investigando o cumprimento de uma das principais obrigações estipuladas pela secretaria da ONU, que consiste no envio anual de relatórios que atestem os progressos obtidos.

Acredita-se que esta prestação de contas se configura como o cerne do pacto, revelandose condição essencial para o alcance de seus objetivos. As comunicações de progresso constituem um ponto de partida cuja ausência impossibilita uma série de análises importantes.

De um lado, as empresas que não comunicam quaisquer progressos obtidos dão margem imediata a um questionamento: o que motivou sua adesão? É sabido que empresas que propagam sua preocupação com a sustentabilidade vem tendo uma valorização, em escala ascendente, por parte da sociedade, o que termina por repercutir em expansão de seu mercado consumidor. Esta motivação configuraria, neste caso, uma postura claramente oportunista. Outra possibilidade seria a adesão a partir do impulso, sendo as organizações estimuladas pela "onda" da sustentabilidade, porém certamente desprovidas do planejamento necessário para materializar as intenções em ações consistentes. Em ambos os casos, embora sob bases éticas diferenciadas, estão empresas que figuram no cadastro consultado como signatárias, quando na prática não o são.

De outro lado, estão as empresas que comunicam as ações realizadas. É a partir destas informações acumuladas que se abrem possibilidades de avanço. Sem elas não há como reconhecer experiências exitosas que podem ser divulgadas de forma a promover sua replicação integral ou o benchmarking para adaptação às especificidades de cada setor, área de negócio ou particularidades regionais.

A principal contribuição deste trabalho foi evidenciar em que patamar se encontra estes dois grandes grupos, ou seja, quem deixa de enviar os relatórios e quem cumpre a referida obrigação. Os números encontrados são, sem dúvida, alarmantes, portanto se espera que os resultados obtidos contribuam para a geração de iniciativas que possam reverter o quadro.

Sabe-se que o fato de encaminhar os relatórios não implica, necessariamente, na existência concreta de progressos, visto que as informações podem ser enviadas sob diversos formatos e em alguns casos relatam apenas ações pontuais e desarticuladas ou carecem de indicadores quantitativos; não se pode ignorar, ainda, as possibilidades de uso de "má fé", resultando em informações que não coadunam com a realidade. 
Constatou-se que a alimentação dos relatórios no site do pacto global segue uma sistemática que se destaca pela agilidade, constituindo um processo bastante simplificado.

Embora seja clara a agilidade proporcionada por esta sistemática, cabe uma reflexão. Se a iniciativa do pacto global tem caráter autorregulatório e voluntário, esclarecendo a própria ONU serem as signatárias as responsáveis integrais pelas informações prestadas, quais seriam as possíveis consequências da publicização das ações sem que haja uma avaliação prévia de sua qualidade e autenticidade? Nestes casos, valeria a pena correr o risco divulgando ações empreendidas sem uma base sólida, que poderiam terminar influenciando de forma negativa outras organizações? Não se pode desconsiderar aqui, a posição que ocupa a Organização das Nações Unidas como instituição de referência com alcance mundial, o que pode fazer com que ações divulgadas a partir dela, ainda que sem a sua "chancela", sejam assimiladas como se a possuíssem.

Está fora do escopo deste artigo a análise dos aspectos qualitativos dos materiais enviados. Tal fato constitui uma limitação do estudo, porém ao mesmo tempo enseja a realização de pesquisas futuras que possibilitem a análise dos conteúdos dos informes enviados, de forma a conhecer relatos de iniciativas que promoveram transformações efetivas no modus operandi das empresas e consequentes benefícios sociais. Outra limitação a ser explorada deve-se ao estudo não ter contemplado as grandes empresas.

Pesquisa exploratória realizada abrangendo dez signatárias revelou que dentre as empresas que enviaram COPs várias apresentaram documentos que não evidenciam qualquer indicador de natureza quantitativa e apenas ações pontuais são listadas. Considerando a elevada inadimplência, a percepção de que mesmo as organizações que comunicam progressos o fazem de forma incompleta evidencia a importância do desenvolvimento de estudos que possibilitem aprofundar a análise qualitativa dos documentos disponibilizados.

Além das recomendações para trabalhos acadêmicos elencamos a seguir algumas sugestões de ordem prática para possível análise pela coordenação do pacto.

A partir do estudo empreendido nos pareceu oportuno que a coordenação da iniciativa global empreenda esforços focados nas empresas ingressantes, no sentido de estimular a aproximação destas às organizações tidas como referência no processo. O reconhecimento de instituições que se destacaram pelos progressos evidenciados abriria uma perspectiva de articulações para melhoria contínua, constituindo-se como um espaço para compartilhamento inclusive das dificuldades vivenciadas por empresas em diferentes fases de participação.

Alinhada a esta colocação está a proposta de atenção diferenciada às empresas de consultoria, em virtude de sua capacidade de influência junto aos clientes atendidos. Percebe-se como oportunidade de expansão deste potencial a implantação de um programa direcionado de orientações.

Outra possibilidade seria vincular a permissão para divulgação da adesão ao pacto a um período de "carência" de um ou dois anos, estimulando a empresa a estruturar-se de forma a atender aos compromissos pactuados, o que evitaria adesões por oportunismo ou impulso sem a devida estruturação que permita a construção de indicadores factíveis e adequadamente confiáveis. 
Uma última recomendação consiste na análise da possível pertinência de uma delimitação mais estreita dos formatos aceitos pela ONU para submissão dos relatórios anuais, pois esta uniformidade diminuiria os custos de um programa de avaliação da qualidade das informações prestadas.

Após a realização deste estudo, conclui-se pela relevância do pacto global para o incentivo de práticas corporativas sustentáveis, percebendo-se, porém como essencial a postura vigilante quanto ao cumprimento dos compromissos pactuados e à divulgação dos avanços alcançados, sob pena de comprometer-se severamente a credibilidade de tão significativa e abrangente iniciativa.

\section{REFERÊNCIAS BIBLIOGRÁFICAS}

1. AFONSO, C. M. Sustentabilidade: caminho ou utopia? São Paulo: Annablume, 2006.

2. AlBUQUERQUE, J. L. Gestão ambiental e responsabilidade social. São Paulo: Atlas, 2010.

3. AREVALO, J. A.; ARAVIND, D. The impact of the crisis on corporate responsibility: the case of UN global compact participants in the USA. Corporate Governance Journal, v. 10, n.4, 406-420, 2010.

4. BARBIERI, J. C.; CAJAZEIRA, J. E. Responsabilidade Social Empresarial e empresa sustentável: da teoria à prática. São Paulo: Saraiva, 2008.

5. BORGES, C.; CORTEZ, F.; PONTES, R. Desenvolvimento: formas e processos. Fortaleza: Fundação Konrad Adenauer, 2006.

6. BOVESPA 2008. Disponível em: http://www.bovespa.com.br/pdf/ISE_Reuniao_Empresas_ Abril2008.pdf. Acesso em: 12 dez. 2011.

7. BRAGA, T.M.; FREITAS, A.P.G.; DUARTE, G.S.; SOUSA, J.C. Índice de sustentabilidade municipal: o desafio de mensurar. Nova Economia, v. 14, n.3, p. 11-33, 2004.

8. CALLADO, A. L. C.; FENSTERSEIFER, J. E. Indicadores de sustentabilidade: uma abordagem empírica a partir de uma perspectiva de especialistas. São Paulo: SIMPOI, 2010.

9. CETINDAMAR, D.; HUSOY, K. Corporate social responsibility practices andenvironmentally responsible behavior: the case of the United Nations global compact. Journal of business Ethics, v. 76, p. 163-176, 2007.

10. CORRAR, L.J.; PAULO. E.; DIAS, J. M., F. Análise multivariada para os cursos de Administração, Ciências Contábeis e Economia. São Paulo: Atlas. 2007.

11. COWEN, S.; FERRERI, L.; PARKER, L. O impacto da característica corporativa na divulgação da responsabilidade social uma análise tipologia e frequência baseado. Organização Contabilidade e Sociedade, v., 12, n. 2, p. 111-122, 1987.

12. DIERKES, M.; PRESTON, L. Corporate social accounting and reporting for the physical environment: a critical review and implementation proposal. Accounting, Organizations and Society, v. 2, n. 1, p. 3-22, 1977.

13. DIMAgGIO, P.; POWELL, W. The Iron Cage Revisited. 2011. Acesso em: 4 dez. 2011. Disponível em: http://www.ics.uci.edu/ corps/phaseii/DiMaggioPowell-IronCageRevisited-ASR.pdf.

14. FERREIRA, D. V. Atitude socialmente responsável ou estratégia comercial: o caso do pacto global. Dissertação de mestrado, Fundação Getúlio Vargas, São Paulo, SP, Brasil. 2008. 
15. FRIEDMAN, T. L. Quente, plano e lotado: os desafios e oportunidades de um novo mundo. Rio de Janeiro: Objetiva, 2010.

16. HEMPHILL, T.A. The United Nations global compact: the business implementation and accountability challenge. International Journal of Business Governance and Ethics, v.1, n.4, p. 303-16, 2005.

17. HERZORG, A.L. (2011, março 11). Assinar parceria com a ONU é a parte fácil. Revista Exame.com. Disponível em: http://exame.abril.com.br/revista-exame/edicoes/0987. Acesso em: 2 dez. 2011.

18. HOURNEAUX, F.; BARBOSA, M.; KATZ, S. A gestão ambiental nas indústrias brasileiras. Anais do Seminário em Administração da FEA-USP, São Paulo, SP, Brasil, 7, 2004.

19. JANNUZZI, P. M.; PATARRA, N. L. Manual para capacitação em indicadores sociais nas políticas públicas e em direitos humanos. São Paulo: Oficina Editorial, 2006.

20. KELL, G. The Global Compact: selected experiences and reflections. Journal of Business Ethics, v. 59, p. 69-79, 2005.

21. KRUGLIANSKAS, I.; ALIGLERI, L.;ALIGLERI, L. A. Gestão socioambiental: responsabilidade e sustentabilidade do negócio. São Paulo: Atlas, 2009.

22. LASZLO, C. A empresa sustentável. Lisboa: Instituto Piaget, 2003.

23. MICHELON, G. Sustainability disclosure and reputation: a comparative study [Working Paper $\mathrm{N}^{\circ}$ 44]. Università Degli Studi di Padova, Padova, PA. 2007.

24. MOKATE, K. Convirtiendo el "monstruo" en aliado: la evaluación como herramienta de la gerencia social. Washington: INDES/BID, 2000.

25. OlIVEIRA, J. A. P.; OGLIARI, C.; PUPO, F. P.; CONTRERAS, F.; COELHO NETO, G.; SMAHA, H. C.; ROCHA, J.; MAEDA, J.; SANTOS, J. M.; PEREIRA FILHO, J.; SALCEDA, J. A.; ALBUQUERQUE, J. R.; MUNIZ, J. P.; GANDOLFI, L.; REZENDE, M.; ZANINI, M. A. R.; GONÇALVES, P.; CALDEIRA, R. C. T.; FARIA, R. F.; VIEIRA, R. P.; BECKER, R.; QUENEHEN, R.; SANTOS, V. H. D. A implementação do pacto global pelas empresas do Paraná. Revista de Gestão Social e Ambiental, v. 2, n. 3, p. 92-110, 2008.

26. GUIMARÃES, R.P.; FEICHAS, S.A.Q. Desafios na construção de indicadores de sustentabilidade. Ambiente \& Sociedade, v. 12, n.2, p.307-323, 2009.

27. RODRIGUES, M. C. P. Projetos Sociais Corporativos: como avaliar e tornar essa estratégia eficaz. São Paulo: Atlas, 2010.

28. SICHE, R; AGOSTINHO, F.; ORTEGA, E.; ROMEIRO, A. Índices versus indicadores: precisões conceituais na discussão de sustentabilidade de países. Ambiente \& Sociedade, v.X, n.2, p.137148, 2007.

29. STROBEL, J. S.; CORAL, E.; SELIG, P. M. Indicadores de sustentabilidade corporativa: uma análise comparativa. Anais eletrônicos do Encontro Anual da Anpad, Curitiba, PR, Brasil, 28, 2004.

30. THÉRIEN, J. P.; POULIOT, V. The Global Compact: shifting the politics of international development? Global Governance, v. 12, p. 55-75, 2006.

31. VEIGA, J.E. Indicadores de sustentabilidade. Estudos Avançados, v.24, n.68, p.39-52, 2010. 
32. _ Indicadores socioambientais: evolução e perspectivas. Revista Economia Política, v. 29, n. 4, p. 421-435, 2009.

33. VERGARA, S. C. Projetos e relatórios de pesquisa em administração. São Paulo: Atlas, 2000. 